\title{
FORMACIONES CANÓNICAS, ARCHIVO Y ARTE LATINOAMERICANO'
}

Natalia Giglietti | nataliagiglietti@gmail.com

Cátedra Teoría de la Historia/Instituto de Investigación en Producción y Enseñanza del Arte Argentino y Latinoamericano. Facultad de Bellas Artes. Universidad Nacional de La Plata. Argentina

\section{RESUMEN}

Este artículo recoge el trabajo realizado durante la residencia de investigación en el Centro de Estudios y Documentación del Museo de Arte Contemporáneo de Barcelona (CED-MACBA). El propósito del proyecto titulado «Archivos activos. Un acercamiento al grupo Escombros desde aquí y desde allá» fue relevar, describir y analizar los documentos relativos al grupo que se encuentran en los fondos pertenecientes al CED. En esta oportunidad, se intentará revisar cómo funcionan los mecanismos del sistema canónico en la conformación del archivo del MACBA y cómo el archivo, en términos teóricos, puede pensarse como canon, es decir, como una forma particular, concreta y localizada en la que se materializa.

\section{PALABRAS CLAVE}

Archivo; formaciones canónicas; arte latinoamericano; Escombros

\section{CANONICAL FORMATIONS, ARCHIVE, LATIN AMERICAN ART}

1 Artículo realizado en el marco del Proyecto de Investigación Archivos, Arte y Cultura Visual entre 1980 y 2001. Acervos personales de artistas y diseñadores de la ciudad de La Plata, acreditado como Proyecto Promocional de Investigación y Desarrollo (PPID-UNLP). Período: 2018-2019. B007. En la redacción del presente artículo, se intentó dejar de lado la utilización del género masculino como universal. En los casos en que esto no ha sido posible, se ha optado por este por razones académicas. Es pertinente aclarar que cada vez que utilizamos los, estamos diciendo las y les, para incluir todas las identidades de género existentes

\section{ABSTRACT}

This article collects the work done in the research residence at the Center for Studies and Documentation of the Museum of Contemporary Art of Barcelona (CED-MACBA). The purpose of the project entitled «Active archives. An approach to the Escombros group from here and from there» was to survey, describe and analyze the documents related to the group that are in the funds belonging to the CED. On this occasion, we will try to review how the mechanisms of the canonical system work in the conformation of the MACBA archive and how the archive, in theoretical terms, can be thought of as a canon, that is, as a particular, concrete and localized form in which it materializes itself.

KEYWORDS

Archive; canonical formations; Latin American art; Escombros 
Entendido como un corpus de obras -el más significativo y, por ello, el más estudiado- el canon se identifica, según señala Anna Brzyski (2007), como un estándar universal de calidad. A pesar de esta constatación, que a simple vista parece vetusta y ampliamente analizada y criticada, la idea persiste y ocupa una privilegiada posición que regula el sistema cultural de valoración.

Comprometida en la problemática del canon, Brzyski advierte que la insistencia en su singularidad esconde su estructura de funcionamiento. Para la autora hablar de canon es reducir su implicancia solo a su contenido, aparentemente único e inalterable. Mientras que el reconocimiento de formaciones canónicas, múltiples y situadas, permite complejizar y especificar sus mecanismos, funciones y alcances en relación con la acción directa de individuos, grupos e instituciones que persiguen diferentes agendas. De modo que una de las principales funciones de las formaciones canónicas, definidas como estructuras discursivas, es organizar la información de acuerdo a un orden jerárquico que produce sentidos culturales, retiene valores y participa en la producción de conocimiento.

A partir de estas primeras descripciones en las que Brzyski desarticula la estructura conceptual del canon, puede señalarse la evidente cercanía con la noción de archivo planteada por Michel Foucault (1969). Según su terminología, el archivo no se refiere a la suma de todos los textos y los documentos que una cultura guarda ni tampoco a las instituciones que permiten registrarlos y conservarlos. Por el contrario, es entendido como un conjunto de reglas que caracterizan a una práctica discursiva, conjunto que, en el análisis de Foucault, lleva el nombre de a priori histórico.

El archivo, entonces, como sistema de enunciados o de la discursividad, es el que define los límites y las formas de lo que es posible hablar y de lo que es considerado válido. Por tanto, podría pensarse al archivo, extrapolando las palabras de Foucault, como una formación canónica particular que produce y mantiene jerarquías a través de aquello que conserva y de cómo lo conserva, es decir, por medio de sus principios de organización y clasificación. A su vez, Brzyski (2007) sugiere que el archivo «determina la relativa visibilidad (y jerarquía) de los enunciados de acuerdo a "regularidades específicas" o criterios de valoración» (p. 11).² La importancia de la ordenación es lo que separa el acto de archivar del de acumular de modo que cada uno de los niveles o grados en los se distribuyen los documentos, y por supuesto las categorías bajo las cuales se disponen, provocan que algunos, más allá de su distancia con el presente, «brillen con gran intensidad como estrellas cercanas, [...] en tanto que otros, contemporáneos, son ya de una extrema palidez» (Foucault, 1969, pp. 219-220).

¿Cuáles son esas estrellas cercanas en el archivo del CED (Centro de Estudios y Documentación)?, ¿en qué tipo de figuras se agrupan o cómo se construyen esas regularidades específicas?, ¿cómo localizar estas formaciones canónicas en el campo particular del archivo?

\section{EL ARCHIVO Y LA COLECCIÓN}

El archivo del Centro de Estudios y Documentación del Museo de Arte Contemporáneo de Barcelona (CED-MACBA) fue creado en 2007, en el marco del proyecto mayor de dotar al museo de un centro de estudios que contenga, a su vez, una biblioteca y un archivo. Con un edificio especial, apartado de las instalaciones del museo, con un presupuesto propio y un equipo de investigadores, restauradores y conservadores, se erigió este centro destinado, en un principio, a ofrecer un servicio de consulta permanente para la comunidad académica [Figura 1], además de la

2 «The archive [...] determines the relative visibility (and hierarchy) of statements according to "specific regularities", or criteria of value» (Brzyski, 2007, p. 11). Traducción de la autora del artículo. 

La adquisición de los fondos del Santa Mónica resultó determinante para justificar la envergadura de semejante proyecto que, año tras año, dejó atrás el pasado de una pequeña biblioteca para adquirir la forma de un colosal espacio institucional que, por momentos, parece desprenderse de la rutina del Museo. El carácter que le otorgó Borja-Villel al MACBA, y a los espacios por donde transitó y transita, ${ }^{3}$ se vuelve evidente en los núcleos temáticos en torno a los cuales se organiza el archivo que, en muchos casos, encuentran su paralelismo en las obras que integran la colección:4 publicaciones de artista, vanguardias o neovanguardias de los años sesenta y setenta, arte conceptual, arte y política, crítica institucional, arte correo, libros de ficción escritos por artistas, feminismos, y, más recientemente, movimientos queer.

En los primeros cuatro ejes se distribuye la presencia latinoamericana, profusamente representada a través de una amplia colección de documentos y de material editado de Edgardo Antonio Vigo y del Centro de Arte y Comunicación (CAYC). A ellos se les suman algunos proyectos, panfletos, producciones colectivas y ediciones de Carlos Ginzburg, de Horacio Zabala y del grupo Escombros, así como también el archivo Tucumán Arde con documentación relativa a las diversas acciones y trabajos del Grupo de Artistas de Vanguardia. De alguna manera, en este sistema de clasificación las palabras clave arte, política y América Latina parecen convertirse en una tríada difícil de desanudar.

La vinculación entre obras y documentos es una cuestión crucial para el CED y aflora recurrentemente en los escritos institucionales, en las palabras de los responsables y en el catálogo digital. La primera tensión surge a raíz

3 La Fundación Antoni Tàpies y el Museo Nacional Centro de Arte Reina Sofía (MNCARS). 4 Por ejemplo, la serie de dibujos, grabados y montajes de León Ferrari como Nosotros no sabíamos (1976) y Nunca más (1995); la proyección performance CC3-Maylerin (1973) que forma parte de la serie Quasi Cinema (Progreso de los experimentos en bloque en el programa Cosmococa), de Hélio Oiticica; las piezas de la serie Atrabiliarios (1993), de Doris Salcedo, o la instalación El día que me quieras (1990), de Alfredo Jaar. del conjunto de libros de artista, la colección documental más relevante del Archivo. La línea divisoria que provoca que los libros de artistas y otros fondos documentales, como el de afiches, formen parte del archivo y no de la colección de arte es un asunto versátil, pues, según la perspectiva por donde se lo observe, va desplazando sus alcances. Uno de los puntos centrales es que, a pesar de este ordenamiento, el MACBA manifiesta que la distinción entre las categorías de obra y de documento se considera superada «al entender que unas y otros integran por igual el continuum que conforma la colección patrimonial del museo, con independencia de cuáles sean los formatos de acceso idóneos en cada caso» (Dávila Freire, 2011, p. 7). De aquí que se haya decidido materializar el posicionamiento a través de la catalogación conjunta, en una misma base de datos, tanto a los materiales del archivo como a las piezas de la colección de arte. Sin embargo, este registro que persigue la intención de desdibujar las jerarquías, parece ser eficaz solo a objetivos internos del Centro de Estudios, pues, en el resultado de las búsquedas a través del catálogo oficial, la clasificación permanece separada en dos pestañas que ya no se nominan obras y documentos, sino archivo y colección.

Los datos arrojados por el buscador acentúan esta problemática sobre los criterios de ordenamiento de estos materiales y sus aparentes continuidades respecto de la colección de arte. Un ejemplo es el conjunto de Vigo que comprende señalamientos, revistas, poemas visuales, correspondencias, catálogos, de los cuales todos son clasificados dentro del archivo y ninguno forma parte de la colección. Una situación contraria, que no deja de ser paradojal, es la que ocurre con el archivo Tucumán Arde, ${ }^{5}$ que integra la colección de arte del MACBA.

5 El archivo se incorpora a la colección artística en el marco de la exposición Antagonismos. Casos de estudio (Barcelona, 2001). En este contexto, el MACBA «adquiere algunos documentos del archivo de Graciela Carnevale (originales repetidos, duplicados y copias) que han circulado en exposiciones internacionales» (Carnevale y otros, 2015, p. 22). 
A raíz de estos casos, puede pensarse no solo que la oposición entre obra y documento se suplanta por otra dicotomía sino que produce, aunque no lo parezca discursivamente, particiones tanto o más polémicas del conjunto patrimonial. Entonces, ¿cuáles son los criterios de valoración que provocan que Tucumán Arde forme parte de la colección y no del archivo y, para la situación inversa, que las producciones de arte correo de Vigo se reúnan en el archivo y no en la colección? Quizás, una de las posibles respuestas tenga que buscarse en el proceso de cierta lógica fetichizadora en la que algunos documentos, restos o registros de propuestas experimentales al ingresar en el territorio del arte hayan devenido en obra. En efecto, puede vincularse con la estructura del canon en función de pensarla como una construcción de tradiciones y de narrativas históricas. Ivo Mesquita (2017) en su artículo sobre el conjunto de piezas latinoamericanas en la colección del MACBA, afirma:

A ellos se les suma el proyecto pionero y radical del archivo Tucumán Arde [...] hoy un jalón en la historia del arte y la política y un punto destacado de la Colección del museo. Es un hito fundacional, una referencia importante para artistas o colectivos (p. 39).

A grandes rasgos, y como sostiene Ana Longoni (2015), Tucumán Arde «aparece, por un lado, como episodio fundante del "conceptualismo ideológico" latinoamericano y, por otro, como "madre" de todas las obras de arte político» (p. 254). De manera que los principios de ordenación ponen de manifiesto una poderosa característica del sistema canónico: la identificación de ciertas obras, o documentos, que definen una particular tradición; en esta oportunidad, ligada a los relatos del conceptualismo global y a sus características regionales. Como argumenta Brzyski (2007) el canon señala un punto fijo de referencia: la tradición cultural occidenta y angloamericana, si se persigue la tendencia del arte conceptual. De aqu que el canon pueda devenir en un lugar de conflicto, en especial, cuando se pone en juego quién define la identidad de un grupo. Esta acepción es particularmente oportuna si se piensa en los debates sobre el estatuto y la inclusión del conceptualismo en la historiografía latinoamericana. ${ }^{6}$

\section{EL CONJUNTO SOBRE ESCOMBROS: ¿UN CASO ANÓMICO?}

Las características bajo las cuales se organizan los documentos del grupo Escombros conducen a repensar este conjunto como un material desatendido y extraño en el universo del archivo. La documentación se presenta diseminada, puesto que algunos materiales forman parte de la colección de afiches y otros tienen una ubicación imprecisa. Resulta dificultoso discernir la colección o el fondo en el que se sitúan más allá de que pueda presumirse que conceptualmente estén vinculados a una sección denominada Documentación generada por artistas y colectivos artísticos. Ante esta situación, ¿nos encontramos frente a un conjunto de documentos que está fuera de la institucionalidad del archivo?, ¿cuáles podrían ser los usos de esta supuesta anomia?, ¿cómo el archivo activa y/o desactiva esta laguna?

Quizás, la escasa cantidad de documentos, la particularidad del colectivo, alejado del modelo del activismo artístico latinoamericano de los sesenta y los setenta, y la tímida vinculación que puede presentar con España, profundizan la aparente ausencia de una norma que pueda cercarlos o ubicarlos en el marco de un relato mayor. ${ }^{7}$ A su vez, al no estar asociados como un grupo integral de materiales se pierde una vez más la comprensión

6 Para profundizar en estos dilemas véase «Fuera de categoría: la política del arte en los márgenes de su historia» (2010), de Jaime Vindel y Ana Longoni.

7 Puede pensarse que sucede algo similar con otros conjuntos como los del CAYC o los de Edgardo Antonio Vigo, sin embargo, a través de las entrevistas realizadas es evidente que más allá de la ordenación concreta en el archivo, por formato o por el nombre del artista, se los vincula directamente con palabras clave como espacios autogestionados y arte correo, respectivamente. Además, es manifiesto el nexo que presentan entre Latinoamérica y Europa. 
de su totalidad, cuestión que podría habilitar otras lógicas de relación y/o de organización. ${ }^{8}$ Todos estos rasgos que conducen, en un primer momento, a concebirlos despojados de toda institucionalidad tienen su contracara en las lógicas propias del archivo en cuanto a sus modalidades de acceso, condiciones de conservación, criterios de inclusión y de acumulación. La llamativa ausencia de categorías ex profeso para la búsqueda y para la clasificación -o, en términos más generales, la inadvertencia- no provoca que se pierdan los motivos del acopio de estos materiales que notoriamente tienen un potencial latente para el museo localizado en su carácter híbrido y periférico. Al respecto, la producción de movimientos y de colectivos que ejercieron reconfiguraciones del status quo intelectual, artístico y político es una temática relevante para el CED que se representa por medio de la marginalidad y la originalidad de la documentación (Dávila Freire, 2011). Hibridez por su doble carácter: artístico y político-social; marginalidad respecto a la oficialidad del arte; y originalidad puesto que, en vista de estas particularidades, para el Centro, no se encuentran en la mayoría de las colecciones institucionales.

De ahí que el acopio de documentos del grupo Escombros presente un marcado interés institucional a pesar de las vagas condiciones bajo las cuales se clasifican, se ordenan y se activan estos materiales. Dada por estas condiciones, la ambivalente anomia parece favorecer una universalización de las propuestas del colectivo, desmarcándolas de la trama en la que fueron producidas.

La mayoría de los documentos que alberga el CED se sitúan entre 1993 y 2002, un período clave tanto en la producción del grupo, por su consolidación luego de cinco años consecutivos de actividad, como por la situación del país en pleno auge de las políticas neoliberales que

8 Refiere a los ordenamientos que presenta el archivo concreto, pues, en los resultados de la búsqueda a través del catálogo digital se presentan agrupados. tuvieron como corolario el estallido económico y social, conocido como crisis de 2001. Entre los nueve materiales que componen el conjunto, se encuentran algunas de las más significativas acciones del colectivo, como la intervención Mar (1993) en el formato de libro-objeto de la colección Biopsia [Figuras 3 y 4]; la multitudinaria convocatoria Todos o ninguno (1995); la pegatina de afiches sobre el asesinato al reportero gráfico José Luis Cabezas (1999); y la publicación del tercer manifiesto La estética de lo humano (2000). ${ }^{9}$
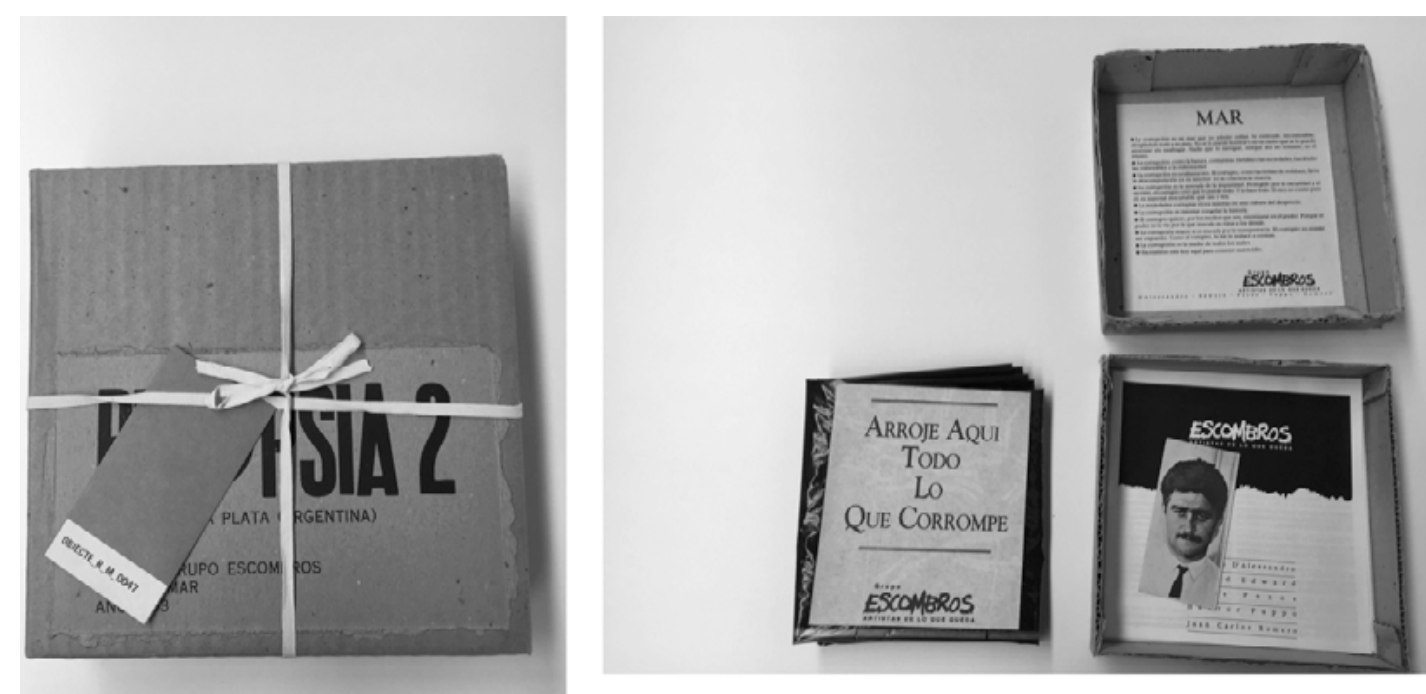

9 Se suman a este listado: dos publicaciones editadas, El bosque de los sueños perdidos (2002) y una cronología de actividades, entre 1988 y 2002, producidas por el colectivo; un panfleto relativo a la obra Monumento Funerario (1993); un catálogo-objeto sobre el mural El hombre roto (1995); y un afiche de la acción El sembrador de soles (2002). Todos ellos ingresaron al acervo del CED en 2010, a través de la donación de la artista Andrea Nacach, con la excepción de Mar, adquirido vía compra en 2009. 


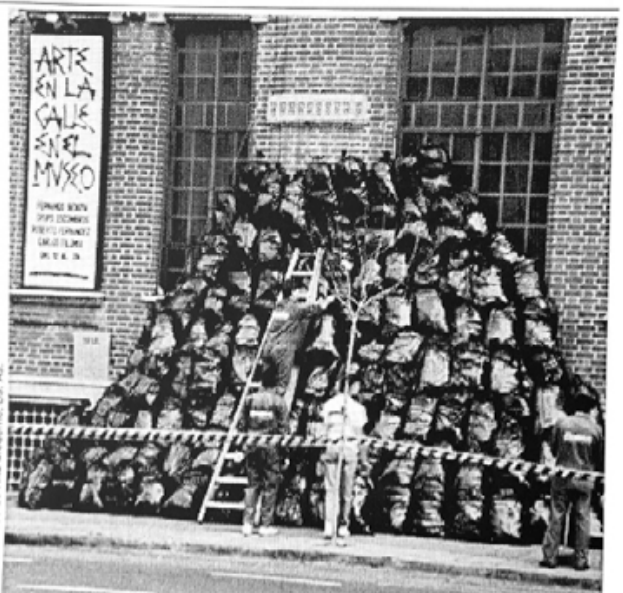

Figuras 3 y 4. Intervención Mar (1993) en el formato de libro-objeto de la colección Biopsia. Grupo Escombros. Centro de Estudios y Documentación del MACBA

De este grupo de documentación solo el libro-objeto Mar salió de los anaqueles del archivo para formar parte de la exposición En los márgenes del arte. Creación y compromiso político (2009), especialmente en el mismo año en el que ingresa al museo [Figura 5]. La muestra curada por Guy Schraener y realizada en el marco de las exposiciones documentales del CED $^{10}$ tuvo como principal objetivo «ilustrar mediante revistas, libros de artista, carteles y octavillas, los diversos entrecruzamientos entre el arte y la implicación política que se dieron durante la segunda mitad del siglo XX» (Schraener, 2009, p. 1). Compuesta por materiales procedentes en su mayoría de movimientos y de artistas europeos, la presencia latinoamericana estuvo dada por Alfredo Jaar, Clemente Padín, Cildo Meireles, Mirtha Dermisache, Edgardo Antonio Vigo y los objetos Biopsia 2 de Escombros y Biopsia 4 de Juan Carlos Romero. ${ }^{11}$

10 Entre las muestras que se realizaron en el espacio de exposición del CED se encuentran: Archivos y documentos (2008); Posibilidades de acción. La vida de la partitura (2008); A XMI. Archivo Xavier Miserachs (2016); Muestreo \#1. Los documentos a escena (2017); Muestreo \#2. This is mail art (2018); Archivo desencajado (2018); Anarchivo sida (2018-2019) y Una archiva del DIY (2019).

11 Refiere a la colección de libros-objeto editados por Edgardo Antonio Vigo. En cada uno de los números, el contenido es elaborado por diferentes artistas invitados por Vigo. El número 2 corresponde a Escombros y el 4 a Juan Carlos Romero.

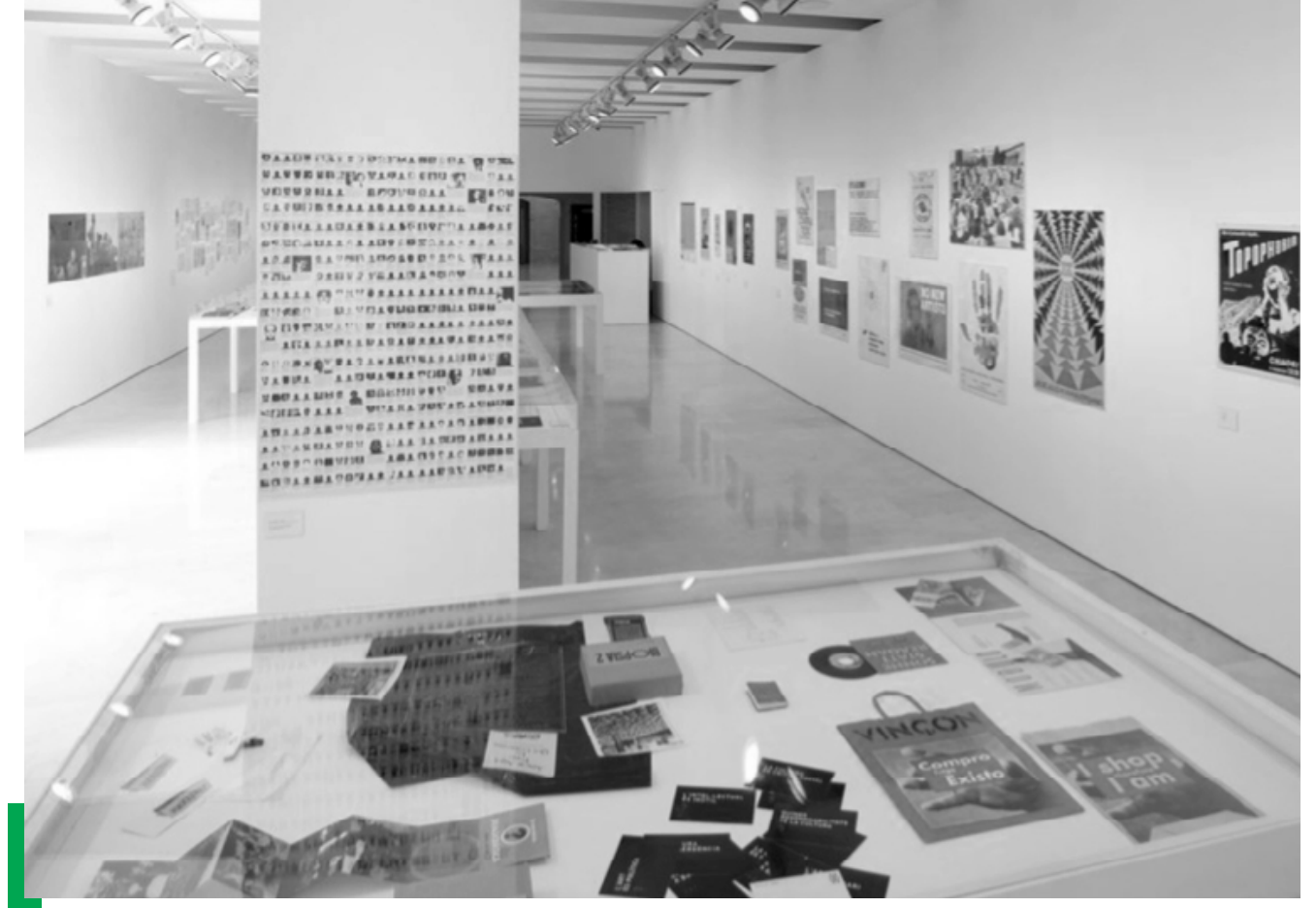

Figura 5. Vista de sala de la exposición En los márgenes del arte. Creación y

compromiso político (2009). Centro de Estudios y Documentación del MACBA

En este contexto, son significativos los amplios ejes a partir de los cuales se seleccionaron las piezas: arte, causas políticas y difusión impresa. Alrededor de estos núcleos se organizaron y homogeneizaron las más diversas producciones con un anclaje muy ligero respecto de las particularidades de cada propuesta y de sus contextos de emergencia. De hecho, la genealogía que propuso el curador para narrar esta historia universal de los cruces entre arte y compromiso político comenzaba con la disposición de dos declaraciones del movimiento surrealista de 1933 y 1936. En el marco de esta convivencia, Mary Memoria de la materia (1997), de Romero, se ubicaron, por ejemplo, junto al disco Sonne Statt Reagan (1982), Joseph Beuys y a las bolsas Compro luego existo (1995) de Barbara Kruger [Figura 6]. De modo que la anomia a la que supuestamente están sometidos los documentos relativos a Escombros parece promover, por lo menos en este caso, ciertos usos del material ligados a ilustrar y oficializar la marginalidad de este tipo de prácticas, y a universalizar las especificidades dentro de un gran relato general. 


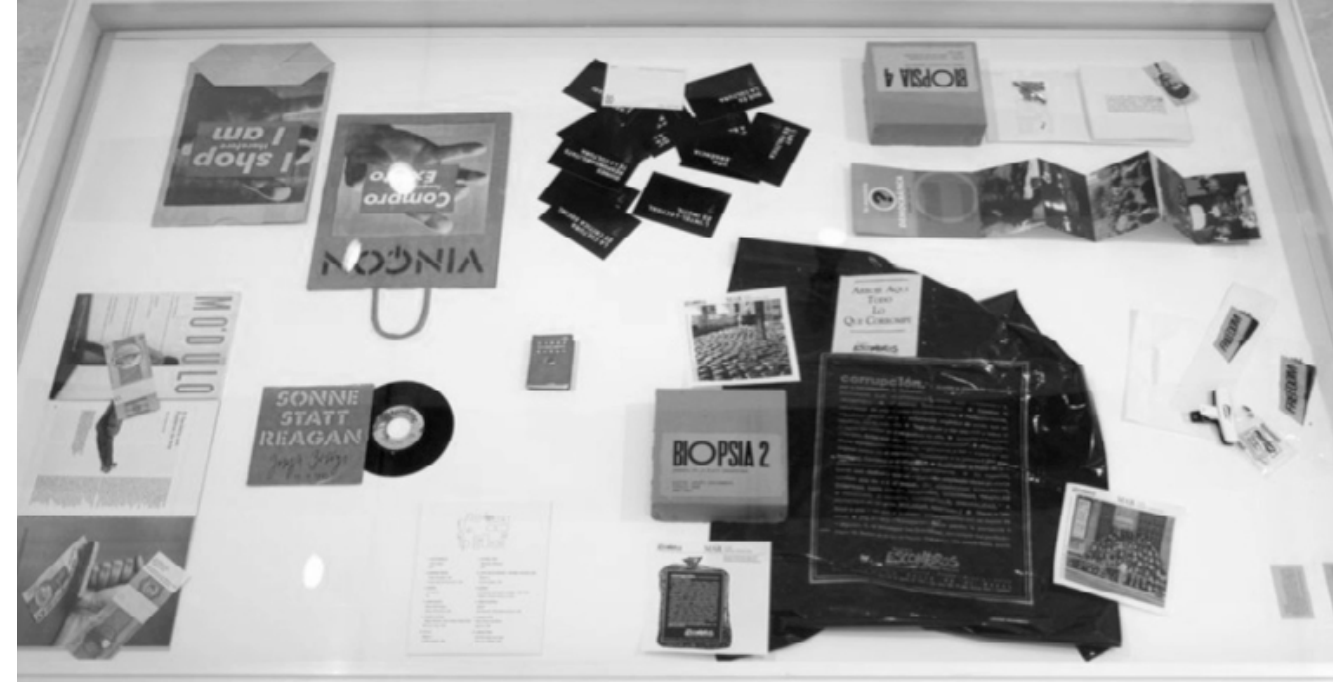
político (2009). Centro de Estudios y Documentación del MACBA

\section{COMO ESTRELLAS CERCANAS}

La lateralidad del archivo, definido por instalarse en una zona intermedia o descentrada entre la colección y la biblioteca, resuena en el lugar que ocupa el MACBA respecto de Madrid o del MNCARS. Dávila Freire (2018) señala:

Barcelona tiene también está condición de lateralidad, sin darle un sentido peyorativo. Es decir, no es ciudad capital y no está en el ojo del huracán, de igual manera que España a nivel político, no está en una posición central con respecto a los países que gobiernan Europa y creo que la cultura latina tampoco lo está en relación con la cultura anglosajona (p. 7).

Esta condición caracteriza, también, algunas de las líneas de adquisición del archivo del MACBA entre las que se encuentran la vinculación entre arte, política y crítica institucional y, en consecuencia - o a modo de usina de ejemplares-, Latinoamérica. El ya clásico y reiterado uso de este tipo de maridaje adquiere en el CED otra faceta ligada al acopio de documentos de propuestas experimentales, en especial, de la década del setenta. Sin embargo, en los últimos años, a la par de la fiebre por los archivos, se ha ido constituyendo, en especial en los archivos españoles, una especie de panteón patriarcal que gira sobre los mismos nombres y sobre los mismos movimientos. De ahí que el canon, y el archivo, puedan ser reconsiderados como una estructura exclusiva y excluyente que opera a favor de intereses de clase, de género y de raza. Griselda Pollock (2008) advierte sobre este asunto al señalar que el archivo está «profundamente impregnado de relaciones de poder, selecciones y exclusiones que contribuyen a predeterminar el sentido del pasado que reconstruimos» (p. 43). El patriarchivo, denominado así por la autora, se rige por la autoridad de aquellos que custodian una colección selectiva de documentos y relatos y sirve para respaldar una ley patriarcal, así como a su base imaginaria y soporte mítico (Pollock, 2008). Bajo este mandato, el CAYC, Vigo, Romero, Pazos, Ginzburg, Zabala y, en menor medida, Escombros, se reiteran en las listas de documentación, tanto en el MNCARS como en el Museo de Arte Contemporáneo de Castilla y León (MUSAC) y en el Archivo Lafuente; ${ }^{12}$ se convierten así en las figuras de los archivos cuando se busca en las producciones argentinas. En cuanto a otros países latinoamericanos, despuntan Clemente Padín, Ulisés Carrión y Guillermo Deisler.

EI MNCARS, con su conocida trayectoria por el interés en archivos de artistas latinoamericanosy sus proyectos en conjunto con la Red de Conceptualismos del Sur, posee un abundante conjunto documental sobre el CAYC, similar a los grupos del MACBA y del Archivo Lafuente, con más de una centena de

12 El Archivo Lafuente fue creado en 2002 por el industrial santanderino José María Lafuente a partir de la decisión de transformar su colección de arte en un fondo bibliográfico y documental. Actualmente, reúne una extensa colección documental especializada en historia del arte del siglo XX en Europa, América Latina y Estados Unidos. 
documentos impresos que ofrecen información sobre las actividades de la espacio. ${ }^{13}$ Vigo, el otro faro de los acervos, se encuentra representado tanto en el MACBA como en el Archivo Lafuente con las ediciones completas de Diagonal Cero (1962-1968) y Hexágono (1971-1975); una gran cantidad de objetos como Múltiples acumulados (1991), Poemas visuales (in) comestibles en caramelos (1995), señalamientos, tarjetas postales, poemas visuales y un conjunto de cartas que intercambió con Pere Sousa y Guillermo Deisler.

En este breve repaso por los conjuntos patrimoniales de los más importantes museos y archivos españoles, el grupo Escombros es un caso llamativo dado que se desprende, parcialmente, de las estrellas del arte correo, del arte político y/o de la crítica institucional. Como se señaló, el conjunto de documentos es relativamente escaso y parece haber sido poco considerado en la narración historiográfica que se construyó alrededor de las décadas del sesenta y del ochenta. De hecho, ni el MNCARS ni el Lafuente parecen albergar materiales documentales sobre el colectivo. ${ }^{14}$ Sin embargo, en ambos se hallan algunas fotografías de la fotoperfomance Transformaciones de masas en vivo (1972-1973), de Luis Pazos. A este conjunto el Reina Sofía suma el políptico y la máscara de La cultura de la felicidad, ${ }^{15}$ y el folleto que acompañó la acción Compañía de excursiones S.R.L (1970), de Luis Pazos, Jorge Luján de Gutiérrez y Héctor Puppo. Por lo que los materiales que atesoran son previos a la conformación del colectivo y dan cuenta más

13 Entre ellos, se destacan escritos fundacionales, registros y objetos de las exposiciones CAYC al aire libre. Arte de sistemas II (1972) y Hacia un perfil del arte latinoamericano. Muestra del Grupo de los Trece (1972), correspondencias entre Jorge Glusberg y Simón Marchán Fiz, diapositivas, anteproyectos y comunicados sobre la clausura de CAYC al aire libre (1972). 14 Es significativo señalar la Universidad de Essex (Reino Unido) en su Colección Essex de Arte de América Latina (ESCALA) conserva un ejemplar de Biopsia 5 así como también otros materiales de Escombros

15 El políptico es un facsímil sobre cartulina del año 2012, compuesto por cinco fotografías y una máscara de la performance que ingresaron, en 2017, a la colección del Museo. de la trama de relaciones que construyó Pazos y del protagonismo que adquirió en esos años en el marco del Grupo de los Trece, ${ }^{16}$ que de un antecedente de Escombros.

Por último, es curioso señalar que otra institución que puede compararse con el CED en cuanto a las características de los materiales que posee sobre Escombros es el Centro de Documentación del MUSAC. El conjunto documental es un espejo del CED: se repiten las mismas publicaciones y objetos como la cronología de actividades, los manifiestos y el catálogo-objeto sobre el mural El hombre roto. No obstante, el período que abarca es entre 2000 y 2004, con excepción de El hombre roto que es la pieza más antigua. También, en perfecta sincronía con el MACBA, y a modo de complemento, se hallan la invitación a la acción El sembrador de soles y la convocatoria El bosque de los sueños perdidos. ${ }^{17}$ Si bien puede identificarse una formación canónica, Escombros, poco a poco, está ocupando un espacio en el podio, o en los términos de Foucault, brilla con mayor intensidad dentro de las colecciones documentales de los museos españoles. De manera que, como indica una vez más Brzyski (2007), contextualizar los cánones es un modo de volverlos presentes, pues como estructuras retóricas no permiten una localización histórica, menos la posibilidad de ser producidos por individuos específicos que persiguen agendas específicas. Ante el reconocimiento de su inevitable presencia, este trabajo se orientó en el análisis de las circunstancias específicas de su producción, desarrollo y funcionamiento en el marco de una esfera particular como es el archivo y, dentro de ella, los documentos de prácticas artísticas latinoamericanas entre las décadas del sesenta y del noventa.

16 El grupo de los Trece (1971), luego grupo CAYC, incluyó inicialmente a Alberto Pellegrino, Alfredo Portillos, Jorge Glusberg, Jacques Bedel, Víctor Grippo, Luis F. Benedit, Juan Carlos Romero, Luis Pazos, Julio Telch, Gregorio Dujovny y Jorge González Mir.

17 Las distinciones se evidencian en la publicación editada por el colectivo Documentos 1: críticas, textos propios, notas periodísticas 2002/2003 (2004) y en los catálogos de exposiciones realizadas, entre 2003 y 2004, en la galería Arcimboldo y en el Museo de Arte Contemporáneo Latinoamericano (MACLA) de La Plata. 


\section{REFERENCIAS}

Brzyski, A. (2007). Canons and Art History [Cánones e Historia del Arte]. En A. Brzyski (Ed.), Partisan Canons (pp. 1-26). Durham y Londres, Inglaterra: Duke University Press.

Carnevale, G., Expósito, M., Mesquita, A., Vindel, J. (2015). Desinventario. Esquirlas de Tucumán Arde en el Archivo de Graciela Carnevale. Santiago de Chile, Chile: Ocho libros

Dávila Freire, M. (2011). ¿Es una obra o es un documento? El Centro de Estudios y Documentación del MACBA. En G. Picazo (Coord.), IMPASSE 10 (pp. 300-308). Recuperado de http://www.macba.cat/uploads/20120612/ Impasse_texto_Mela_CAST_maq.pdf

Foucault, M. (1969). Arqueología del saber. Ciudad de México, México: Siglo Veintiuno.

Giglietti, N. y Sedán, E. (2018). Archivos públicos y privados. Las instituciones entre el dominio histórico y el artístico. Entrevista a Mela Dávila Freire. Nimio. Revista de la cátedra Teoría de la Historia, (5). doi: 10.24215/24691879e006

Longoni, A. (2015). El mito de Tucumán Arde. En G. Carnevale, M. Expósito, A. Mesquita, J. Vindel, Desinventario. Esquirlas de Tucumán Arde en el Archivo de Graciela Carnevale (pp. 253-265). Santiago de Chile, Chile: Ocho libros.

Mesquita, I. (2017). Un repositorio latinoamericano en la Colección MACBA. En F. Barenblit, C. Dercon, A. Grandes, I. Mesquita, A. Perelló, Colección MACBA. Una selección (pp. 33-39). Recuperado de https://www.macba.cat/ uploads/20171123/ivo_mesquita_esp.pdf
Pollock, G. (2008). Desde las intervenciones feministas hasta los efectos feministas en las historias del arte. Análisis de la virtualidad feminista y de las transformaciones estéticas del trauma. En X. Arakistain y L. Méndez (Dirs.), Producción artística y teoría feminista del arte. Nuevos debates I (pp. 43-63). Vitoria, España: Centro Cultural Montehermoso Kulturunea.

Schraener, G. (2009). En los márgenes del arte. Creación y compromiso político [Catálogo de exposición]. Recuperado de https://www.macba.cat/ uploads/20090819/Margenes_CEDOC_cas.pdf

Vindel, J. y Longoni, A. (2010). Fuera de categoría: la política del arte en los márgenes de su historia. El Río sin orillas. Revista de Filosofía, Cultura y Política, (4), 300-336. 